\title{
Evaluation of the gravimetric method of propofol infusion with intermittent ketamine injections for total intravenous anaesthesia (TIVA)
}

\author{
FE Amadasun and NP Edomwonyi
}

\begin{abstract}
Forty four patients scheduled for elective surgery of short to moderate duration $(<90$ minutes) were recruited into this study. Anaesthesia was induced with intravenous propofol $2.5 \mathrm{mg} / \mathrm{kg}$ and maintained with continuous intravenous infusion of pre-mixed propofol and normal saline containing $2 \mathrm{mg} / \mathrm{ml}$ of propofol. Suxamethonium $1 \mathrm{mg} / \mathrm{kg}$ was used to facilitate endotracheal intubation. No long-acting muscle relaxant was used. Intravenous ketamine $0.5 \mathrm{mg} / \mathrm{kg}$ stat dose was given for analgesic supplement, and $0.25 \mathrm{mg} / \mathrm{kg}$ subsequent intermittent doses on signs of inadequate anaesthesia. The propofol infusion was stopped at the end of the surgery. Mean duration of anaesthesia was $56.5 \pm 2.6$ minutes while mean recovery time was $10.6 \pm 4.6$ minutes. The mean post-anaesthetic recovery scores (PARS) were 4.35/6, 5.17/6, 5.80/6 and 5.85/6 at admission to the recovery room and after 15 minutes, 30 minutes and discharge to the ward respectively. There were no incidents of extreme haemodynamic fluctuations or emergence phenomena noticed in any of the patients.
\end{abstract}

\section{INTRODUCTION}

Total intravenous anaesthesia (TIVA) entails the use of intravenous (IV) drugs for the induction and maintenance of general anaesthesia. Inhalational anaesthetic agents have been used for decades with improving safety and efficacy. In spite of this, there is renewed interest in TIVA. Several factors have contributed to this, including possible organ toxicity of some inhalational agents like halothane, and the effects of operating theatre pollution

\begin{tabular}{c} 
KEY WORDS: $\begin{array}{c}\text { Anaesthesia, infusion, methods, } \\
\text { haemodynamic, emergence, gravimetry }\end{array}$ \\
\hline
\end{tabular}

Department of Anaesthesiology, University of Benin Teaching Hospital, Benin City, Nigeria. on personnel. Possible environ-mental damage caused by nitrous oxide and the halogenated volatile anaesthetics like depletion of the ozone layer and the "green house effect" is also a serious concern. The contribution of anaesthetic agents to these hazards is small but significant. ${ }^{1,2}$

There are certain procedures like bronchoscopies and laryngoscopies, where the use of inhalational drugs is difficult or impossible. The use of nitrous oxide may be contraindicated in situations where its penetration into enclosed cavities could result in extensive damage including operations in the middle ear, intestinal surgery or in patients with pneumothorax. A suitable alternative in such scenarios is TIVA. 
Among the strongest impetus for the growth of TIVA has been the development of drugs like propofol, alfentanil and atracurium, whose pharmacokinetic properties allow rapid clearance from the body with minimal hangover effects. The development of accurate delivery systems like the computerised syringe infusion pumps has been an added advantage. The use of computerised infusion pumps in TIVA has been likened to the use of vapourisers with inhalational anaesthetics. Despite this advantage, the infusion pump is expensive and may not be affordable in poor societies that may wish to adopt TIVA services.

An alternative method of TIVA administration is the age-old gravimetric method of continuous intravenous infusion whereby the IV anaesthetic is pre-mixed in the infusion container with a suitable crystalloid IV fluid and allowed to flow under gravity. This study was designed to assess the effectiveness of TIVA using the gravimetric method of propofol infusion, with intermittent subhypnotic IV ketamine injections as analgesic adjunct. The quality of anaesthesia, drug consumption, recovery characteristics and undesired effects were evaluated.

\section{MATERIALS AND METHODS}

The study was prospective, sequential and carried out among adult elective surgical patients at the University of Benin Teaching Hospital. Institutional ethical approval and informed patient consent were obtained. Only patients for short to moderate duration surgery ( $<90$ minutes) and whose operations were feasible without use of muscle relaxants were included in the study. All the patients were of physical fitness status ASA 1 or 2. The patients were visited in the ward the day before surgery for pre-operative assessment and to prescribe pre-medication. This consisted of oral diazepam 10mg on the morning of surgery.

In the operating theatre, monitors were attached, baseline vital signs were recorded and intravenous line set up. A propofol infusion fluid mixture was set up by withdrawing $100 \mathrm{ml}$ from a 500ml normal saline infusion bag, and adding $100 \mathrm{ml}$ propofol (5 ampoules of $200 \mathrm{mg}$ each). This gives a mixture of $2 \mathrm{mg} / \mathrm{ml}$ of propofol. The patients were pre-oxygenated for about three minutes and anaesthesia was induced with $2.5 \mathrm{mg} / \mathrm{kg}$ IV propofol. Suxamethonium $1.5 \mathrm{mg} / \mathrm{kg}$ was given IV to facilitate endotracheal intubation. Anaesthesia was maintained with the pre-mixed propofol infusion at a flow rate that was titrated to the desired depth of anaesthesia. A stat sub-hypnotic dose of ketamine $0.5 \mathrm{mg} / \mathrm{kg}$ was given IV, with repeat $0.25 \mathrm{mg} / \mathrm{kg}$ doses if patient moved or showed other signs of inadequate analgesia/anaesthesia such as lacrimation, rise in pulse rate or blood pressure. All the patients breathed spontaneously, as no long-acting muscle relaxants were used.

Throughout the operation and anaesthesia, the patients were closely monitored for haemodynamic stability, drug consumption and adequacy of analgesia/anaesthesia. About 10 minutes to the end of surgery, the propofol infusion was stopped and the patient allowed to recover from anaesthesia. The airway was suctioned and the trachea was extubated. Patients were subsequently discharged to the recovery room.

In the recovery room, patients' vital signs, including pulse rate and blood pressure, and the level of consciousness were monitored and recorded. The post-anaesthetic recovery level was assessed and scored using the Seward post-anaesthetic recovery score (PARS). ${ }^{3}$ The scores on arrival in the recovery room, at 15 and 30 minutes, and at discharge to the ward were recorded. The results were analysed and rational conclusions deduced.

\section{RESULTS}

The patients' demographic data were as presented in Table 1. All patients in the study lost consciousness with the administration of 
the induction dose of propofol. The mean induction dose of propofol was $160 \pm 26.8 \mathrm{mg}$. Induction of anaesthesia was smooth, without any patient exhibiting excitatory side effects like involuntary movements, hiccups or sneezing. Five patients complained of pain on injection of propofol. The mean dose of propofol to maintain anaesthesia was $577.3 \pm$ 28.5mg. This was delivered by continuous IV infusion from the pre-mixed propofol/normal saline infusion bag. The rate of propofol delivery was $12 \mathrm{mg} / \mathrm{kg} / \mathrm{hr}$ for the first ten minutes, and subsequently titrated to desired depth of anaesthesia. Supplemental intermittent sub-hypnotic bolus injections of ketamine were given statim and on signs of inadequate analgesia such as movement to surgical stimuli. Average number of bolus ketamine injections was $3.7 \pm 1.9$, delivered in aliquots of $0.5 \mathrm{mg} / \mathrm{kg}$ at a time. The mean total dose of ketamine injected was $78.2 \pm$ $28.0 \mathrm{mg}$. The mean duration of surgery was $50.3 \pm 2.6$ minutes and the mean duration of anaesthesia was $56.5 \pm 2.6$ minutes. These are
Table 1 Patients' Demographic data

\begin{tabular}{ll}
\hline Age (years) & $34.1 \pm 15.4$ \\
Sex ratio (male/female) & $20: 24$ \\
Weight & $57.5 \pm 7.0$ \\
ASA status & 1 or 2 \\
\hline
\end{tabular}

depicted in Tables 2 and 3 . The range of surgery on the patients is illustrated in Table 4 .

The mean time to awakening after cessation of propofol infusion was $10.6 \pm 4.6$ minutes. Awakening was judged by the ability of patients to respond to verbal commands such as eye or mouth opening. In the recovery room, average total post-anaesthetic recovery score (PARS) was 4.35/6, 5.17/6, 5.80/6 and 5.85/6 at admission, after 15 and 30 minutes, and at discharge to ward respectively. The total PARS and component scores at the different times are illustrated in Table 5. Average stay in the recovery room was $45 \pm 13.6$ minutes. There were no incidents of extreme haemodynamic fluctuations or emergence phenomena in the peri-operative period in any of the patients.

\section{Table 2 Mean dosages of propofol and ketamine used}

Induction dose of propofol

Maintenance dose of propofol

Total dose of propofol per patient

Number of bolus ketamine injections

Mean total dose of ketamine per patient
$160 \pm 26.8 \mathrm{mg}$

$577.3 \pm 28.5 \mathrm{mg}$

$737.3 \pm 30.2 \mathrm{mg}$

$3.7 \pm 1.9$

$78.2 \pm 28 \mathrm{mg}$

\section{Table 3 Type of surgery}

\begin{tabular}{lc}
\hline Type of surgery & Number of patients \\
\hline Excision/biopsy & 16 \\
Tonsillectomy & 8 \\
Maxillofacial surgery & 4 \\
Haemorrhoidectomy & 6 \\
Urethrotomy & 3 \\
Thyroglossal fistulectomy & 2 \\
Gynaecological examination under anaesthsia & 5 \\
\hline Total & 44 \\
\hline
\end{tabular}


Table 4 Post-anaesthetic recovery score (after Steward ${ }^{3}$ )

\begin{tabular}{lrrrr}
\hline & $\begin{array}{c}\text { On admission to } \\
\text { recovery room }\end{array}$ & At 15 minutes & At 30 minutes & $\begin{array}{r}\text { At discharge from } \\
\text { recovery room }\end{array}$ \\
\hline $\begin{array}{l}\text { Conscousness level } \\
\text { (Max.score }=2 \text { ) }\end{array}$ & 1.50 & 1.42 & 1.90 & 1.90 \\
$\begin{array}{l}\text { Airway function } \\
\text { Max. score }=2)\end{array}$ & 1.40 & 1,85 & 1.90 & 1.95 \\
$\begin{array}{l}\text { Motor function } \\
(\text { Max. score }=2)\end{array}$ & 1.45 & 1.90 & 1.95 & 2.00 \\
$\begin{array}{l}\text { Total score } \\
(\text { Max.score }=6)\end{array}$ & 4.35 & 5.17 & 5.80 & 5.85 \\
\hline
\end{tabular}

\section{DISCUSSION}

The use of drugs for intravenous anaesthesia is not new. The first recorded intravenous injection was a mixture of opium by Sir Christopher Wren in $1674,{ }^{4}$ which resulted in the (unintentional) production of unconsciousness. Unfortunately, Wren was unaware of the possibilities of his observation. It would take another 200 years before the concept of anaesthesia to prevent the suffering associated with surgery became acceptable. Twenty five years after the demonstration of nitrous oxide and ether anaesthesia, the Frenchman Pierre-Cypriene Ore used intravenous injection of chloral hydrate to anaesthetise patients for ophthalmic surgery. ${ }^{5}$ In the intervening years, various substances have been tried as intravenous anaesthetics including such unlikely drugs as ether, chloroform and ethanol. ${ }^{4}$ Few of these have stood the test of time and, today, only a few drugs are considered suitable for TIVA.

TIVA, as currently practiced, uses several types of drugs, each performing a specific role to produce balanced anaesthesia. The overriding objective is to have rapid clearance rates and little delay between changes in infusion rates, serum level and pharmacological action. This allows for rapid and accurate adjustment of anaesthesia. Virtually all IV induction agents have been tried for TIVA, but they have been largely abandoned. Midazolam, used in TIVA, causes prolonged postoperative sedation, particularly after infusion for more than one hour. Despite this, the drug has been used successfully for TIVA, with opioid supplementation with or without nitrous oxide. ${ }^{6}$ Ketamine has potent analgesic properties besides its anaesthetic potency. It is not suitable for the maintenance of anaesthesia in TIVA, as it has a long recovery period due to drug accumulation and active metabolites. In adults, at least, it may cause worrisome psychotomimetic effects during recovery (emergence phenomena). At low doses $(0.5-1.0 \mathrm{mg} / \mathrm{kg})$, however, it is an effective analgesic agent. Moreover, due to its sympathomimetic properties, it enhances cardiovascular physiology by causing release of endogenous catecholamines, though it is a direct cardiac depressant. ${ }^{7}$ Its sympathomimetic efficacy makes it a good adjuvant to propofol, which is a cardiovascular depressant. ${ }^{8}$

Propofol is widely used for rapid smooth induction of anaesthesia. It has a high clearance rate and rapid decline in blood concentration. This makes it suitable for use in continuous intravenous infusion and maintenance of anaesthesia in TIVA. When the infusion is stopped, there is rapid recovery from anaesthesia, which is due to both redistribution and metabolism. In this study, the average recovery time from anaesthesia was $10.6 \pm 4.6$ minutes. Studies have shown that the speed and quality of recovery from propofol-based TIVA is superior to that obtained with most inhalational anaesthetics. ${ }^{9,10}$ 
Methods of propofol delivery for TIVA vary from intravenous infusion pumps to gravimetric continuous intravenous infusion and intermittent IV bolus injections. We used the gravimetric method in this study to evaluate the anaesthetic profile of the method and to ascertain its suitability for TIVA.

This is pertinent, since the infusion pump is expensive, and not many centres possess them. We did not use muscle relaxants in the study to enable us to discern the depth of anaesthesia and minimise incidents of awareness. In modern classical TIVA, however, a balanced anaesthetic regime would consist of the appropriate anaesthetic, analgesic and muscle relaxant agents.

When Velghe-Lenelle et $\mathrm{al}^{11}$ compared the infusion pump and gravimetric methods of propofol-based TIVA, there were no significant differences between the two groups in terms of propofol consumption, number of interventions to manage depth of anaesthesia, recovery time and haemodynamic stability. Nevertheless, Vinuesa et al, ${ }^{12}$ after a retrospective study, opined that computerised infusion pumps for TIVA improved standardisation. This may be so, but when infusion pumps are unavailable, safe and effective TIVA can still be delivered as demonstrated in this study.

We used ketamine as an analgesic adjunct in this study. Modern TIVA usually relies on the newer exotic opioids like fentanyl, alfentanil and congeners for analgesic adjunct. Again, these are relatively expensive and are not commonly available in many third world centres. They have the advantage of rapid onset and short duration of action, which are desirable in TIVA. Ketamine on the other hand tends to accumulate in the body with prolonged or repeated usage. This may delay recovery from anaesthesia. However, the intermittent bolus injections given to maintain analgesia as used in this study tend to minimise total administered dose. The mean total ketamine consumption in this study was $78.2 \pm 28 \mathrm{mg}$. With a mean patient weight of $57.5 \mathrm{~kg}$, which comes to a dose per unit weight consumption of $1.36 \mathrm{mg} / \mathrm{kg}$, given over an average duration of anaesthesia of 56.5 minutes. With this regimen, the mean post-anaesthesia recovery score (PARS), using the Seward's scale, ${ }^{3}$ was $4.35 / 6$ on admission to the recovery room and 5.85/6 45 minutes later on discharge to the ward. This, coupled with the mean recovery time of 10.6 minutes, shows that this regime permits an appreciably fast recovery from anaesthesia.

Eshiet et $\mathrm{al}^{13}$ observed that intermittent bolus ketamine injection as sole anaesthetic is associated with greater sympathetic stimulation and haemodynamic instability, compared to continuous IV infusion of ketamine. Wide haemodynamic fluctuations were not observed in our study, as ketamine was not a sole anaesthetic agent but an analgesic adjunct to propofol TIVA. Propofol has cardiovascular depressant properties as a result of nitric oxide release, which acts as a calcium channel blocker and activates protein kinase C. ${ }^{15}$ Thus, the two drugs, ketamine and propofol, tend to complement each other to maintain cardiovascular stability when used in TIVA.

Another drawback of ketamine anaesthesia is the post-anaesthesia emergence phenomena it is associated with. Eshiet et $\mathrm{al}^{13}$ found a higher incidence of these features in patients with continuous IV infusion, compared to intermittent IV bolus injections. This is due in part to the higher total consumption of ketamine with such method. Emergence phenomena were not observed in our patients, partly because of the relatively low dose ketamine consumption and partly due to the benzodiazepine pre-medication used.

\section{CONCLUSION}

Safe and effective anaesthesia can be administered with propofol-based TIVA using the gravimetric method of drug delivery. Whereas it is fashionable to use exotic opioids like alfentanil as analgesic adjunct in such practice, intermittent IV bolus ketamine in- 
jections could be a viable alternative in less endowed circumstances. The absence of a computerised syringe infusion pump should not be an impediment to providing TIVA services. The use of the gravimetric method of drug delivery comes very handy in such situations.

\section{References}

1. Logan M and Farmer JG. Anaesthesia and the ozone layer. Br J Anaesth 1989; 63: 645-647.

2. Blustein H. Anaesthetic agents and the ozone layer. Anaesth Int Care 1990; 18: 102-109.

3. Steward DJ. A simplified scoring system for the post-operative recovery room. Can Anaesth Soc J 1975; 22(1): 111-113.

4. Bovil JG. Total intravenous anaesthesia - a pharmacokinetic approach. $M$ East $J$ Anaesthesiol 1995; 13: 37-60.

5. Ore PC. Des injections intravenueses de chloral. Bull Soc Chirurgie Paris 1872; 1: 400.

6. Persson MP, Nilsson A, Hartrig $P$ and Tamsin A. Pharmacokinetics of midazolam in total I.V. anaesthesia. Br J Anaesth 1987; 59: 548-556.

7. Sota Omoigui. In: The Anaesthesa Drug Handbook, Ketamine. St. Louis: Mosby Year Book, 1992; 98-99.

8. Guit JBM, Koning HM and Coster ML. Ketamine as analgesic for total intravenous anaesthesia with propofol. Anaesthesia 1991; 46: 24-27.
9. Nightingale JJ and Lewis IH. Recovery from anaesthesia: a comparison of total intravenous anaesthesia with an inhalational technique. $\mathrm{Br} J$ Anaesth 1990; 65: 287-288.

10. Puttick N and Rosen M. Propofol induction and maintenance with nitrous oxide in paediatric outpatient dental anaesthesia. A comparison with thiopentone-nitrous oxide-halothane. Anaesthesia 1988; 43: 646-649.

11. Velghe-Lenelle CE, Barvais L, Coassaert E, Cantraine F and d'Hollander A. TIVA with propofol in general surgery: manual compared with a new object oriented programmable TCI system. $\mathrm{Br} J$ Anaesth 1996; 76(suppl. 2): A30.

12. Vinuesa J, Vinuesa F, Cantraine F, Barvais L and d'Hollander A. Free access of PC- controlled infusion devices results to further standardization of TIVA in adult cardiac surgery: a retrospective quality control study. Br J Anaesth 1996; (76 suppl. 2): A31.

13. Eshiet AI, Akpan SG and Akpan IE. Comparison of intermittent bolus injections and continuous infusion of ketamine for total intravenous anaesthesia. Afr J Anaesth Int Care 2001; 4(1): 14-16.

14. Bilota F, Fiorani L, La Rossa I, Spinelli and Rasa G. Cardiovascular effect of intravenous propofol administered at two infusion rates: a transthoracic echocardiographic study. Anaesthesia 2001; 56(3): 266-271.

15. Cook DJ and Housmans PR. Mechanism of negative inotropic effect of propofol in isolated ferret ventricular myocardium. Anesthesiology 1994; 80: 859-871. 